\title{
Issues of consent and the primary-school medical
}

P Bradley National Institute of Public Health, Oslo, Norway

\begin{abstract}
This article discusses what level of consent is needed from a child or parent before a primary-school medical can take place (ie where children are aged under 12). It also considers whether there are occasions when a doctor can see a child if the parents have failed to give consent or have explicitly refused consent.

Primary-school children are considered incompetent to make decisions about their own medical treatment and so their consent does not need to be gained before a medical takes place, although it is highly desirable to obtain it. However, a doctor cannot justify a decision to see a child purely in terms of the benefit conferred on the child. Parents can be wronged if their wishes are ignored and usually those wishes should be considered overriding. Normally, general consent, which need not be fully informed, is needed before a school medical. However, if a child is considered to be in danger of being harmed significantly or suspected to have a major medical condition, a medical should go ahead regardless of the level of consent obtained from the parent, so that a reasonable standard of health is maintained for the child.

(Fournal of Medical Ethics 2000;26:469-472)
\end{abstract}

Keywords: School medical; conflict of interest; consent; professional ethics

\section{Introduction}

Legally, in the UK, only general consent is needed from patients before medical treatment can be started. However, there may be occasions when informed rather than general consent is more desirable. Informed consent would involve an explanation of the risks and benefits of a particular medical procedure. The level of consent that is needed before medical procedures are carried out is an issue which arouses great debate, ${ }^{12}$ especially in connection with procedures where the patient is otherwise fit and well, for example screening procedures. ${ }^{3}$ However, in some instances of screening procedures the requirements of general consent are not even met, for example where school medicals are carried out in the absence of parental consent.

\section{What happens in a primary school medical? \\ Typically, the school medical can include:}

- a medical assessment at school of children selected by age (usually school entry) or because of professional concern
- a statutory medical assessment, for example, for children under social services and educational supervision

- a medical for children with previously recognised medical problems

- an emergency service for children, especially on matters of child protection..$^{4-6}$ (Northampton Community Health NHS Trust: letter:12.2. 1995) (Bradford Community Health NHS Trust: letter: 13.3.1995)

The nature of the examination (both verbal and physical) varies with each child according to the concerns raised, if any. There is, however, a standard procedure for the school-entry medical. The questions asked of each attending parent at the medical are very similar. The physical examination, which includes inspection of the male genitalia, is a complete physical examination. It includes, however, no internal examination. The school-entry medical is also a developmental assessment, which should be a relatively pleasant experience for most children.

\section{What is the procedure by which consent is usually obtained?}

Usually, a written invitation is sent to parents via the child or through the post and the parent is invited to complete a health questionnaire and consent form. The parent can:

- accompany the child to the appointment

- request another appointment

- give permission for the child to be seen in parental absence

- refuse consent for the child to be seen

Ideally, all parents would consent and attend their child's medical. If no response is received, the child may, in some schools, be seen by the doctor despite parental absence and the lack of parental consent. One justification for this policy is an assumption that the non-consenting parents' children will have a higher than average prevalence of significant medical problems and will include some children about whom there is serious professional concern. The former policy is questioned by professional organisations such as the British Medical Association (BMA) (British Medical Association: letter: 1.6.1994) and the Department of Health (Department of Health: letter: 12.2.1995). The BMA considers that the parent's wish to choose may override 
the doctor's duty of care. In some health authorities, a doctor never sees a child unless a parent has explicitly given permission or accompanies the child (South Buckinghamshire Community Health NHS Trust: letter: 18.4.1995) (South Downs Community NHS Trust: letter: 16.2.1995) (Hull and Holderness Community Health NHS Trust: letter: 27.3.1995) (Southern Community Health NHS Trusts and Southern Health and Social Services Board: letter: 4.4.1995).

The major role of a community doctor is to promote the health and wellbeing of all children, particularly those who are not accessing other existing health services. ${ }^{7-9}$ The organisation and effectiveness of this role has recently been questioned and the importance of communication between health care workers and parents has been emphasised. ${ }^{31011}$ We will assume, however, that school medicals generally benefit children and that many parents support them.

\section{What is the legal basis for consent?}

Usually English law requires consent from a patient before a medical procedure. ${ }^{12}$ General consent involves a doctor disclosing sufficient information for the patient to understand the nature and procedure of proposed health care in broad terms only. This usually requires a level of disclosure consistent with standards set by the medical profession..$^{14} \mathrm{~A}$ duty to inform the patient further is not legally necessary for school medicals. Even general consent is not always necessary, for instance, the doctor may act without the patient's consent in some emergencies, ${ }^{12}$ so long as the action is seen to be taken in the child's "best interests". 15

Parents usually have a legal right of refusal to treatment of their child if the treatment is either optional or of disputed clinical value. ${ }^{16}$ Arguably, a school medical falls into both these categories.

In the case of children, it is assumed in law that all children under the age of ten years will not have sufficient competence to refuse or consent to medical treatment. ${ }^{16}$ In view of this fact, the parents or guardians are usually given the power to consent or refuse medical treatment for their children. ${ }^{16}{ }^{17}$ Their wishes are seen to be evidence of the child's best interests. Most children in primary school are below ten years of age.

In England, there have been no legally successful cases against a doctor or health worker which have resulted from a screening procedure being undertaken for a child in the absence of parental consent It is unlikely that such litigation would succeed if the child had not been harmed by the procedure and the doctor had been clinically competent. ${ }^{18}$

\section{Is informed consent necessary before a school medical?}

Obtaining informed consent might allow parents to feel in control of medical care offered to their children and empower them to care for their children's health themselves. ${ }^{19}$ If the doctor has an overriding duty to inform the parent of the risks and benefits of the school medical prior to initiating it, the doctor will need to obtain informed consent from the parent before every medical. Informed consent is not obtained either because: the parents do not reply and cannot be located; the parents refuse consent; the doctor does not disclose sufficient information, or the "consent" is given in written form, before the medical, for the child to be seen in the parent's absence.

\section{Informed consent - what is it?}

Informed consent is a more complex notion than a patient's simply authorising treatment. Definitions of informed consent are varied and complex, so it is only possible to identify some common elements to these definitions here.

Informed consent necessitates that: relevant information is disclosed by the doctor to the patient; the patient understands this information; the patient is able to consider and make a decision about whether to agree to the proposed treatment (the patient needs to be competent to make this decision); this decision is made voluntarily, ie, the decision maker makes a decision when free to choose or refuse treatment, and the patient authorises the treatment to take place. ${ }^{2021}$

\section{Does consent need to be informed for a school medical?}

For consent to be informed, we at least expect the nature, consequences and risks of the medical to be understood by the parent. If parents do not attend or are not told enough about the medical for their child, they may only have a vague idea about what the medical entails. They may not appreciate, for instance, that the doctor will inspect a boy's genitalia to test for testicular descent. We might argue that this is not informed consent. On our definition, this is not informed consent, as relevant facts have not been understood.

Quite apart from this, the consequences of the medical are likely to be beneficial. A condition may be misdiagnosed or the child upset emotionally but the risk of long-lasting harm will usually be very small. Even if consenting parents do not fully appreciate the nature of the school medical, they are agreeing to a procedure of low risk and probable benefit for their child. Informed consent should ideally be obtained for prudential reasons as cited earlier, but is not absolutely necessary.

So if informed consent is not required, is general consent needed from children and parents for a school medical or can a medical go ahead solely because it benefits the child?

Can we justify overruling a child's wishes? If a child refuses an examination, it is difficult to gain any useful information. Usually, the prudent course of action is to re-invite the child who will then have gained enough confidence to allow the 
medical to take place. There may be occasions, however, when a medical is immediately required or when a child refuses the medical on repeated occasions.

Many writers feel that a child's level of autonomy is related to competence and so, when a child refuses a medical, they argue, it must be because the child's autonomy is not fully developed. Competence is seen as a threshold above which children can make their own decisions about the health care offered to them. ${ }^{16-22}$ Buchanan and Brock also note that a child's development usually increases the ability to be competent. By their criteria, this is achieved at around 15 years. ${ }^{23}{ }^{24} \mathrm{Set}-$ ting such limits has been criticised as arbitrary but it is obvious that the competence of a younger child to make decisions about health care is less than that of an older one. ${ }^{24} 25$

Buchanan and Brock and others also note that psychologists feel that children up to the age of 12-13 consider that the locus of control in their lives is external to them. ${ }^{26}$ This is obviously an important factor in appreciating why a child's decision about health care should not be overriding. If others easily sway children, the doctor and society may have a duty of care to protect children from harm even against their own wishes.

This criterion of maturity might allow us to distinguish why a parent's view could be regarded as competent and not a child's. Parents' experience and knowledge bolster their maturity. Children are not expected to be responsible for decisions about their health. Many writers consider they are too suggestible to be allowed to choose at primaryschool age. ${ }^{212527}$ The responsibility for the child's health lies with parents or guardian and society. Health and social services represent society in this context.

\section{Can the doctor conduct a medical when the parent has explicitly refused consent or when consent has not been obtained?}

Whether a doctor might justifiably override a parent's wishes in order to reveal the health problems of the child is more controversial.

Doctors may decide to see a child without parental consent because they consider that, in view of their specialist knowledge, they are in a better position to know how to promote the child's health than a parent. Seeing the child may ensure that the child avoids potential harms and achieves net benefits. Avoiding these harms or securing these benefits may be seen as too important to be overridden by the parent.

Clearly, there are occasions when the doctor can act against parental wishes. For example, a schoolteacher refers a child to the doctor because he has been repeatedly coming to school covered with bruises. The father is contacted and the situation openly explained by the doctor. The doctor explains that the child must be examined or referred to social services. The father refuses to allow this. The doctor's statutory and moral duty is to ensure the child is assessed as the child's life may be at stake. ${ }^{27}$

This latter point is illustrated further by cases where parents intend to act in the "best interests" of their children but disagree with the opinions of doctors on how best to achieve this, for example, Jehovah's Witness parents refusing a blood transfusion for their child. In such life and death cases, the law states that it is wrong for the parent to interfere with the child's right to receive health care..$^{1826} 28$

Although action in such extreme cases is seen as clear cut in our society, this does not mean that a doctor can usually act to promote the best consequences for the child against the parent's wishes.

\section{Vaccination}

There are problems in justifying why a doctor might act against parental wishes in non-extreme situations. Parental opinion is usually considered of major significance in deciding whether a child should receive health care and the doctor does not always know what is best for the child. There are difficulties for health professionals in making prognoses and benefit-to-burden calculations. Some writers suggest that the parent is better placed to make these calculations. ${ }^{29}$ For instance, it is not acceptable in law for a doctor to give a child a vaccination without the parent's consent. ${ }^{12}{ }^{15}$

It seems therefore that doctors must at least consider parental views. Doctors can neither anticipate the results of the medical nor the possibility of parental gratitude. Nor can they assume retrospective consent. ${ }^{30}$ If a doctor persists with a medical when a parent has refused or not given consent, $\mathrm{s} / \mathrm{he}$ could wrong the parent. Specifically, parents are no longer able to choose health care for their children and may even suffer long term damage, such as losing confidence in their adequacy as parents.

We might argue, however, that no matter what the parent's views, a "reasonable standard of health" for the child must be maintained. If we make this assumption, a doctor would be justified in carrying out a medical for any child who was suspected of failing to maintain a "reasonable standard of health", even if consent had been refused. Such a medical might have to be carried out under the supervision of the social services, who have statutory powers to organise this.

A "reasonable standard of health" might be defined as being free from all major health problems. The existence of minor problems that do not directly harm the child's long term health, although considered significant by some professionals, would not be included in this definition, for example, having mild temporary hearing loss. Although it might be difficult to classify some conditions, most of those inconsistent with a reasonable standard of health would be easily recognised by both doctors and parents.

For example, a medical is requested for a child with hearing loss, but a parent refuses consent. The decision whether to hold a medical against parental consent would depend on the suspected severity of 
the child's hearing loss, the impact of the loss and the likelihood that treatment would be successful in helping the child's condition. If the hearing loss was severe and there was a reasonable chance that treatment could help the child, a doctor might be justified in pursuing a medical assessment without parental consent. However, if the hearing loss and learning difficulties were mild, temporary and no effective treatment were available, then the medical should not go ahead, as the parent could be wronged by the assessment and there would be no discernible benefit for the child.

\section{Conclusion}

Primary-school children are considered incompetent to make decisions about their own medical treatment and so their consent does not need to be gained before a medical takes place, although it is highly desirable to obtain it. A doctor cannot, however, justify a decision to see a child purely in terms of the benefit conferred on the child. Parents can be wronged if their wishes are ignored and usually those wishes should be considered overriding. Normally, general consent, which need not be fully informed, is needed before a school medical. If a child is considered to be in danger of being harmed significantly or suspected to have a major medical condition, however, a medical should go ahead regardless of the level of consent obtained from the parent, so that a reasonable standard of health is maintained for the child.

\section{Acknowledgements}

I would like to thank Jennifer Jackson, Director of the Centre for Professional Ethics at Leeds University, who helped me prepare arguments used in this article.

P Bradley, MRCGP, DCCH, MFPHM, MA (Health Care Ethics), MPH, is Consultant in Public Health Medicine, National Institute of Public Health, Department of Health Promotion and Prevention/SAFH, Oslo, Norway.

\section{References}

1 General Medical Council. Seeking patients' consent: the ethical considerations. London: General Medical Council, 1988
2 British Medical Association. Medical ethics today: its practice and philosophy. London: BMJ Publishing Group, 1993:1-35.

3 Hall D, ed. Health for all children: a programme for child health surveillance. Oxford: Oxford University Press, 1989:12.

4 Sklaire MW. Role of the paediatrician in school. Paediatrics in Review 1990;12:69-70.

5 British Paediatric Association. Health services for school age children: consulation report of the joint working party. London: British Paediatric Association, 1993: 5.

6 Department of Health. Child health in the community: a guide to good practice [consultation draft]. London: HMSO, 1995: 31.

7 Goldberg ES. School physicians: what they do and why they are needed. Fournal of Developmental and Behavioural Paediatrics 1982;3:179-81

8 Boyce WT, et al. Survey of physician consultation in an urban school district. Fournal of School Health 1983;53:308-11.

9 Oberklaid F. Role of the school doctor. British fournal of Hospital Medicine 1993;49:765-6.

10 Committee on Child Health Services. Court report: fit for the future vol 1. London: HMSO, 1976: Cmnd 6684.

11 National Children's Bureau. Child health ten years after the Court report: report of the policy and practice review group. London: NCB, 1987.

12 Brazier M. Medicine, patients and the law. Harmondsworth: Penguin, 1992: 73-4.

13 Bolam v Friern HMC [1957] 1 WLR 582.

14 Sidaway v Board of Governors at Bethlem Royal Hospital [1985] 1 All ER 643.

15 Bainham A, Creaney S. Children: the modern law. Jordan, 1993: 250-5.

16 See reference 11:341-3.

17 Dworkin G. The theory and practice of autonomy. Cambridge: Cambridge University Press, 1988: 85.

18 Holder A. Legal issues in paediatric and adolescent medicine. Yale University, 1985: 264

19 Stone GC. Patient compliance and role of the expert. Fournal of Social Issues 1979;35:34-59.

20 Alderson P. Choosing for the child. Oxford: Oxford University Press, 1990: 107-10.

21 Beauchamp TL, Childress JF. Principles of biomedical ethics. Oxford: Oxford University Press 1994:138-49.

22 Kennedy I, Grubb A. Medical law: the text and materials. London: Butterworth Press, 1989: ch 4: 181-2.

23 Buchanan AE, Brock W. Deciding for others: the ethics of surrogate decision making. Cambridge: Cambridge University Press, 1989: 22-3.

24 Archard D. Children, rights and childhood. London: Routledge, 1993: 4-5.

25 Kennedy I. The doctor, the pill and the 15-year old girl. In: Lockwood M, ed. Moral dilemmas in modern medicine. Oxford: Oxford University Press, 1985:37-9.

26 See reference 22: 220-36.

27 Children Act part v: protection of children. London: HMSO, 1989: ch 41: 38-52.

28 See reference 17: 102-3.

29 See reference $20: 170-84$

30 Goldstein J. Medical care for the child at risk: on state supervention of parental autonomy. Yale Law fournal 1977;86: $645-70$. 